\title{
Nephrocutaneous Fistula after Microwave Thermal Ablation and Literature Review
}

\author{
Marius Anglickis ${ }^{1 *}$, Giedre Anglickiené2 ${ }^{2}$ Gintarè Andreikaité ${ }^{1}$, Lina Miklyčiūtè ${ }^{1}$ and Edmundas Štar- \\ olis $^{1}$ \\ ${ }^{1}$ Department of Urology, Vilnius City Clinical Hospital, Lithuania \\ ${ }^{2}$ Department of Chemotherapy, National Cancer Institute, Lithuania
}

*Corresponding author: Marius Anglickis, Department of Urology, Vilnius City Clinical Hospital, 10207 Vilnius, Lithuania, Tel: +3706-752-6279

\begin{abstract}
Nephrocutaneous fistula is a very rare complication of renal surgery. It may be associated with renal tumors, nonfunctional kidneys, staghorn calculi, renal trauma or chronic urinary tract infections. Because of widely used imaging techniques an early detection of small renal tumors has modified the management of kidney cancer. Nephron sparing surgical resection remains the standard of care for T1 tumors less than $7 \mathrm{~cm}$. For patients who are not amenable for surgery, microwave thermal ablation (MWA) is gradually becoming a preferred treatment modality. In this article we present a rare complication after microwave thermal ablation for small tumor. For a 75-year-old patient a CT was performed: Two tumors were identified. One tumor was $16 \mathrm{~mm}$ in diameter, the second one was $37 \times 28 \times 44 \mathrm{~mm}$. Biopsy was performed before MWA. Papillary adenocarcinoma G2, I type was found. Microwave thermal ablation of right renal tumor was performed for 15 minutes $35 \mathrm{~W}$. The patient was released. Two weeks after an MWA urine started leaking from the needle insertion area. It was decided to insert a ureteral stent, but the stenting was complicated. After 3 month radical nephrectomy was performed. A histological examination was performed - no residual tumor was found.
\end{abstract}

\section{Introduction}

Nephron sparing surgical resection remains the standard of care for T1 tumors less than $7 \mathrm{~cm}$. A common treatment for small renal cell carcinoma usually is kidney resection, however it has been noticed that open surgery is more often followed by postoperative complications as well as higher risks. Resection of the kidney is the first line treatment method for patients with small renal carcinoma and without any other serious comorbidities. However, the elderly, who are the main group of people diagnosed with this type of cancer, usually have multiple comorbidities. They have much more risk factors for perioperative and postoperative complications. Major surgeries requiting general anesthesia should be avoided for older patients and those with high-risk comorbidities, including severe cardiovascular and pulmonary diseases. For patients who are not amenable for surgery because of comorbidities, advanced age, who already have precarious kidney function, who have solitary kidney or prefer less invasive treatment option, the percutaneous approach is feasible. There are three main percutaneous image-guided ablative therapies in use: Radiofrequency ablation, cryoablation, and microwave ablation. In each case, one or more needles are inserted into the tumor and energy (heat or freezing) is used to destroy the tumor. Ablation therapies are associated with less treatment related morbidity and mortality than resection. The different techniques vary in terms of time needed for treatment, ability to monitor the process, and other patient and tumor dependent factors. Radiofrequency ablation and cryoablation may present limitations in terms of efficacy for tumor greater than $3-4 \mathrm{~cm}$. Microwave thermal ablation may be beneficial in this setting. During MWA consistent higher intratumoral temperatures are provided than during other ablation procedures. Because of lack of studies with midto long-term follow up there's insufficiency of data

Citation: Anglickis M, Anglickienė G, Andreikaitė G, Miklyčiūtė L, Štarolis E (2019) Nephrocutaneous Fistula after Microwave Thermal Ablation and Literature Review. Int Arch Urol Complic 5:066. doi. org/10.23937/2469-5742/1510066

Accepted: December 11, 2019: Published: December 13, 2019

Copyright: (c) 2019 Anglickis M, et al. This is an open-access article distributed under the terms of the Creative Commons Attribution License, which permits unrestricted use, distribution, and reproduction in any medium, provided the original author and source are credited. 
to determine the efficacy and oncologic outcomes of this technique. Most common complications after MWA are microscopic hematuria, perirenal hematoma, thermal injury of psoas muscle. Massive bleeding requiring blood transfusion is reported to have an incidence of 1 to 2\% [1]. Major complications of renal microwave ablation are 2 to $6 \%[2,3]$. Less common complications: Thermal injury of pelvicalyceal system, diarrhea, abdominal distension, edema of lower limbs, hydrothorax, bowel injury, genitofemoral nerve injury. Tumor seeding around the needle tract is an extremely rare complication after renal ablation. The incidence of ureteral thermal injury is 1 to $2 \%$ and it has been suggested that ureteral injury can be avoided when the ureter is located more than $1 \mathrm{~cm}$ from the ablation zone. Nephrocutaneous fistula is a distressing clinical condition. The fistula can be very difficult to treat and has a high chance of recurrence.

\section{Case Report}

75-years-old woman presented with right kidney tumor using ultrasound. Two tumors were detected on CT (Figure 1). The conclusion of a CT scan: In the right kidney mid/lower pole $16 \mathrm{~mm}$ in diameter hypervascular tumor, more endophytic, about $7 \mathrm{~mm}$ till the collecting system of the kidney (Nephrometry scale 5 a). The second tumor in the right kidney is approximately $37 \times 28 \times 44$ in size, located in the upper/

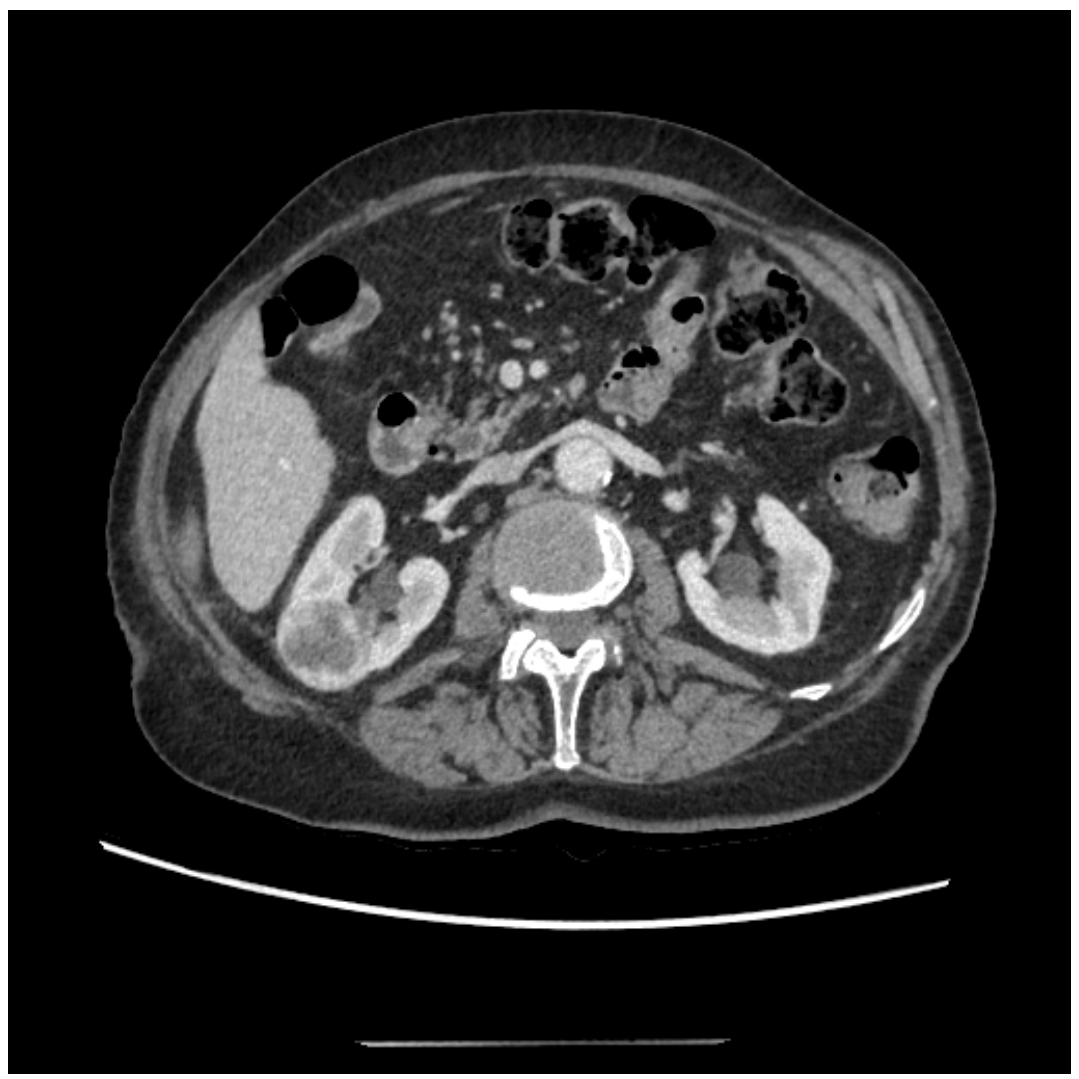

Figure 1: Two tumors were detected on CT.
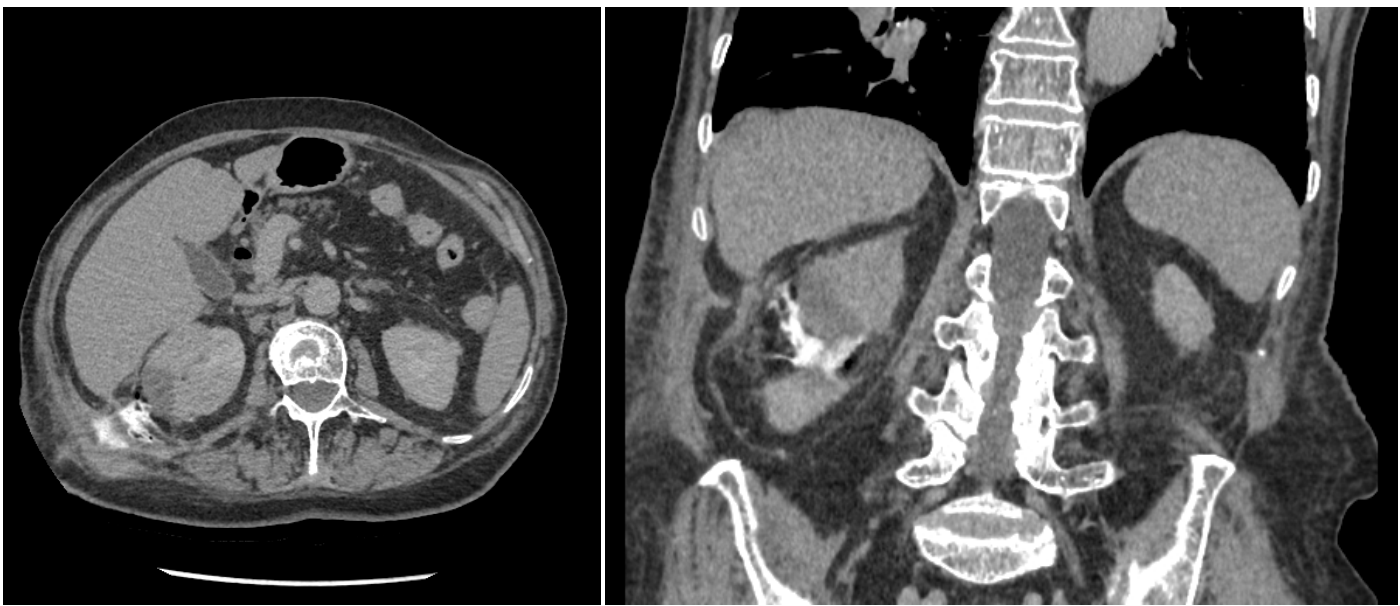

Figure 2: CT was performed: Fistula from the mid calyx was found. 
mid thirds of the kidney, more laterally, polycyclic, nonhomogeneous with necrosis, unevenly accumulates contrast agent, more endophytic, in contact with collecting system of the kidney. A biopsy was performed. Moderately-differentiated (G2) papillary adenocarcinoma, I type was found. Under intravenous anesthesia, percutaneous ultrasound-guided microwave thermal ablation was carried out. Under ultrasound guidance two short tip needles were inserted into the tumors and microwave thermal ablation was performed for 15 minutes using $35 \mathrm{~W}$. The tumors changed in visually as were seen on ultrasound. The needles were removed after procedure. No perioperative or post-operative complications were observed. After 2 weeks a large amount of urine began to leak through the puncture site on the right flank. Approximately 1.5 I of urine on a daily basis. CT was performed: Fistula from the mid calyx was found (Figure 2). Collection of fluid around the fistula, by the abdominal wall. It was decided to put a stent in the right ureter. Nephrostomy was technically impossible due to the absence of hydronephrosis. Because of ureteral stenosis, ureteroscopy was unsuccessful. Right ureteral stenting was performed under the $X$-ray control. Position of the stent was appropriate. The patient was released home. There was no urine coming through the fistula, but after two weeks, the leaking of urine reoccurred. After two months patient was admitted to the hospital for ureteroscopy and the replacement of the stent. The urologist was unable to perform ureteroscopy because the proximal end of the stent was in the infiltrated tissue, probably outside the ureter. It was impossible to replace the stent, the stent was removed. Due to excessive discharge of the urine through the fistula and erythema it was decided to perform right kidney resection, but it was technically unavailable because of fibrosis and suppuration of the surrounding tissues. Nephrectomy was performed. Post-operative time without any complications. Histological examination showed no residual papillary adenocarcinoma in the kidney.

\section{Discussion}

Nowadays, microwave ablation, radiofrequency ablation and cryoablation are the most popular thermal ablative techniques. Age, comorbidity, patient's desire for minimally invasive treatment, hereditary disease, solitary kidney and decreased renal function were considered to be the main indications for MWA. It is an effective treatment modality for the elderly, patients with comorbidities, hereditary kidney tumors. Microwave thermal ablation has also become an applicable treatment of small kidney tumors. It is less invasive and morbid treatment option, offers many advantages of other ablation techniques and several additional (faster ablation time, the possibility to use multiple applicators at the same time, higher intratumoral temperatures, less painful procedure). There is insufficient data and studies to determine the oncologic effectiveness of renal microwave thermal ablation but it appears to be safe and effective in the treatment of T1 tumors. Major complication rate is quite low. Overall, the rates of major complications with renal ablation are 2 to 6 [4]. Inadvertent injury of the proximal ureter during renal ablation has been associated with formation of a urinoma, ureteral obstruction, and chronic stricture. The incidence of ureteral thermal injury is 1 to $2 \%$. It has been suggested that ureteral injury can be avoided when the ureter is located more than $1-2 \mathrm{~cm}$ from the ablation zone . Injury to the kidney collecting system, urinomas may occur from perforation of any portion of the collecting system. Nephrocutaneous fistula is a rare but serious complication of renal surgery. The nephrocutaneous tracts usually heal spontaneously once the distal drainage from the kidney is ensured but in rare cases they may persist. In our case drainage of the kidney collecting system with nephrostomy or stent was unsuccessful. Therefore nephrocutaneous fistula remained for a long time after the MWA was performed. Kidney resection was technically impossible due to highly expressed fibrosis of the perinephric tissues. CT or MRI are usually performed 1 month after the MWA. We recommend doing the next day after the MWA procedure. It would allow to evaluate the efficacy of the MWA, identify such complications and begin their treatment early. Partial nephrectomy, though technically challenging in a revisited scenario, is the best option for the patient and should be done if technically possible.

\section{References}

1. Park BK, Kim CK (2009) Complications of image-guided radiofrequency ablation of renal cell carcinoma: Causes, imaging features and prevention methods. Eur Radiol 19: 2180-2190.

2. Maybody M (2010) An overview of image-guided percutaneous ablation of renal tumors. Semin Intervent Radiol 27: 261-267.

3. Atwell TD, Farrell MA, Leibovich BC, Callstrom MR, Chow GK, et al. (2008) Percutaneous renal cryoablation: Experience treating 115 tumors. J Urol 1796: 2136-2140.

4. Maybody M (2010) An overview of image-guided percutaneous ablation of renal tumors. Semin Intervent Radiol 27: 261-267. 